\title{
CAPítULO 9
}

\section{BRASIL, BRUZUNDANGAS E O NOVO MANIFESTO \\ ONDE BOLSONARO E O MANDACHUVA SE CONFUNDEM}

Natália Barbosa Gomes Vago ${ }^{46}$

\section{RESUMO}

Este capítulo investiga a construção da identidade e das representações da política brasileira por meio das vozes e dos discursos dos personagens de Lima Barreto e seu reflexo na atualidade, levando em conta a análise literária crítica que se empreende a partir do enredo dos contos Os bruzundangas e O novo manifesto, salientado o modo como a literatura pode mostrar o contexto histórico de determinados grupos sociais presentes nas obras, através do conjunto narratológico, resultado de um nacionalismo ufanista que, ao mesmo tempo, constrói um retrato da política brasileira atual.

Palavras-Chave: Lima Barreto; conto; política; crítica social.

\footnotetext{
46 Mestre em Estudos da Literatura pela UFF. Docente da SME de Volta Redonda. E-mail: nataliabgomesvr@yahoo.com.br.
} 


\section{INTRODUÇ̄̃o}

Candido (1987) assegura a influência estética, cultural e crítica de formações acadêmicas europeias no preparo do pensamento e da mentalidade nacional, apresentando a postulação de que a presença do pensamento europeu teve forte influência na interação e reiteração da criação artística. Mesmo na posição de imitadores das escolas literárias estrangeiras, da colônia à república, Candido salienta a força de ruptura da escrita sul-americana:

\footnotetext{
Nos países da América Latina a literatura sempre foi algo profundamente empenhado na construção e na aquisição de uma consciência nacional, advertindo, nesse processo, que o ponto de vista histórico-sociológico é indispensável para estudá-la (1987, p. 180).
}

A busca por uma literatura realmente nacional remonta ainda ao Romantismo, principalmente no que tange à valorização da língua e da paisagem nacional e demonstra aversão aos costumes de origem estrangeira, tentando imprimir nas artes valores genuinamente brasileiros, passando pelo Realismo e pelo Naturalismo, que procuravam mostrar a realidade de maneira crua. A consciência nacional regulava-se como uma temática literária inclusa nos propósitos que davam ênfase a um nacionalismo identitário. Surgia, no cenário brasileiro da virada do século XIX para o XX, um discurso literário ufanista que, gerado pela arte literária, tentou contrabalançar uma série de caracteres críticos diversificados.

Nos primeiros anos da República, o Brasil foi governado por militares. A República da espada durou cinco anos (1889 a 1894), sendo sucedida por uma dobradinha entre os estados de Minas Gerais e São Paulo. A República café-com-leite, formada por cafeicultores paulistas e produtores de leite mineiros durou de 1884 a 1930, quando Getúlio Vargas ascende ao poder.

Enquanto o mundo vivia o período da belle époque, mas sob a sombra de uma possível guerra, o que fazia com que alguns países começassem uma corrida armamentista, o Brasil era um país de contrastes, como ainda é atualmente.

Nos grandes centros e no interior do país, os antigos escravos, agora livres, eram marginalizados e os europeus, sobretudo italianos, que chegavam ao país para substituir a mão de obra escrava não encontravam uma situação muito melhor: as condições de trabalho eram aviltantes (ambiente de trabalho insalubre, longas horas de trabalho, baixa remuneração) tanto no campo quanto nas parcas indústrias. O Nordeste do país sofria com o cangaço, a seca e a estagnação econômica. Aqueles que sobreviviam eram deixados à própria sorte. Desalentados pela desesperança e procurando solução divina para males de origem econômica, 
foram facilmente arregimentados por beatos de seitas místicas, cujo maior exemplo foi Antônio Conselheiro, fundador da comunidade de Canudos, onde foi travada uma guerra, entre 1896 e 1897, no estado da Bahia.

Esse período histórico foi marcado por guerras, revoltas e o crescimento das greves e movimentos operários em São Paulo. O Rio de Janeiro, até então capital do país, foi palco de duas grandes revoltas: da Vacina e da Chibata. E é nesse cenário que surge Afonso Henriques de Lima Barreto.

Nascido no Rio de Janeiro em 1881, de origem humilde, estudou no Colégio Pedro II e na Escola Politécnica, que teve de abandonar por problemas financeiros, sem concluir o curso. Trabalhou como jornalista e foi funcionário público na Secretaria de Guerra. O alcoolismo levou-o à morte prematura em 1922, ano do início do movimento modernista no Brasil.

Lima Barreto construiu sua história como autor dentro de um período conturbado e controverso: o Pré-Modernismo. Foi o pensador e crítico literário Alceu Amoroso Lima que utilizou pela primeira vez, em 1939, o termo PréModernismo como forma de designar a produção literária brasileira das duas primeiras décadas do século XX, sendo esse período compreendido entre $1900 \mathrm{e}$ 1922, caracterizado pela convivência de várias correntes literárias, com predominância do Parnasianismo. O Pré-Modernismo procurava denunciar os problemas da realidade brasileira, fazendo face à chamada literatura sorriso da sociedade. Não é considerado, propriamente, uma escola literária. Apenas designa um período no qual poucos escritores procuraram interpretar a realidade brasileira, revelando suas tensões e os problemas sociopolíticos da época.

Lado a lado com a miséria do povo, estava o mundo cor-de-rosa da elite. E poucos eram os escritores que procuravam denunciar essa realidade. Os grandes autores estavam mais preocupados com o prestígio social que a literatura poderia trazer. Assim sendo, faziam vista grossa para o mundo que os rodeava e frequentavam saraus e cafés, apreciavam palavras difíceis, eram adeptos dos maneirismos europeus e do tom retórico parnasiano, produzindo uma literatura voltada para o público de maior poder aquisitivo.

Rompendo com os modelos literários da época, houve o aparecimento de uma nova classe de escritores, por sua vez, engajados, que viam, na produção literária, uma forma de renovar a vida social e o que se considerava como a cultura brasileira. Entre eles, estava Lima Barreto que, contrariando alguns dos seus contemporâneos, procurou nas classes mais populares e no desmascaramento da vida cotidiana da pequena burguesia a matéria de suas obras. O uso do sarcasmo com o qual ironizava os políticos e escritores da sua época fez com que fosse 
pouco apreciado no seu tempo. Some-se a isso o uso de uma linguagem mais coloquial (o que reflete o seu desprezo pela retórica parnasiana), considerado desleixo por alguns, que lhe valeu muitas críticas. Inseriu sua carreira em um contexto de formação e emancipação literárias, começada em 1907, com a criação e publicação da Revista Floreal, até 1922, ano da grande protrusão literária, com a chegada da Semana de Arte Moderna.

\footnotetext{
Para Candido, Lima Barreto procurou romper com a literatura meditativa e ligada à produção estética predominante e adotou uma arte compromissada com a formação do homem no seu contexto; uma arte voltada para a análise do social em relação ao individual; uma escrita direcionada para os outros, para a vida humana: Para Lima Barreto a literatura devia ter alguns requisitos indispensáveis. Antes de mais nada, ser sincera, isto é, transmitir diretamente o sentimento e as ideias do escritor, da maneira mais clara e simples possível. Devia também dar destaque aos problemas humanos em geral e aos sociais em particular, focalizando os que são fermento de drama, desajustamento, incompreensão (1987, p. 39).
}

Barreto edificou, no período político em que foi contemporâneo, sua obra em três funções: compromisso, direcionamento e engajamento. O posicionamento formador do autor se solidifica à medida que intervém na sociedade em que viveu de maneira crítica.

Segundo Candido: A literatura, encarada com vida na qual a pessoa se realiza, parece então substituto de sentimentos ou experiências, e este lado subjetivo não se destaca do outro, que é o seu efeito e o seu papel fundamental: estabelecer a comunicação entre os homens (1987, p. 40).

É possível perceber traços biográficos na obra de Lima Barreto, como no livro Recordações do escrivão Isaías Caminha, personagem que sofre reveses na vida por conta da cor de sua pele. O autor também utiliza elementos da realidade em sua obra, como personagens reais feito Floriano Peixoto, que aparece em Triste Fim de Policarpo Quaresma.

Santiago (2000, p. 11) afirma que o discurso latino-americano baseia-se na dualidade entre a disputa de formas e manifestações culturais de resistência e formas culturais padronizadas e alicerçadas nos padrões academicistas europeus. A produção literária de Lima Barreto encontra-se sob essa perspectiva, aproximando-se de novas maneiras de fazer arte, libertando-se de padrões canonizados pela estética clássica, ao mesmo tempo em que procura legitimar o que escreve, apresentando uma dicotomia entre a elite e o povo, o centro e a periferia etc. De maneira crítica e reflexiva, abusando da ironia e do sarcasmo, Barreto abre um novo caminho na vereda das letras nacionais, tanto no campo da estética 
quanto no conteúdo temático, tendo como cerne de sua produção o fazer literário e a discussão política.

Assim como em suas outras obras, na composição dos temas de Os bruzundangas e $\mathbf{O}$ novo manifesto, Lima Barreto encontrou inspiração no cotidiano da cidade que conhecia e onde nasceu e morreu: o Rio de Janeiro. Munido desse conhecimento, fez a transposição para o universo ficcional, sobretudo com a política, que ocupa grande parte de sua produção literária.

\section{BRUZUNDANGAS: REFLEXOS DE UMA POĹLIICA DOENTIA NA DESCONSTRUÇÃOO DE UM PAís}

Literatura e política seguem de mãos dadas na produção literária de Lima Barreto, assim como de tantos outros que ousaram pensar que toda uma nação também se enxergaria naqueles que são marginalizados, fazendo face a uma literatura que não tinha preocupação com a realidade. Por isso, foi de suma importância o surgimento de uma literatura militante na obra de Barreto.

A partir dessa denúncia da realidade, chega-se ao conto Os bruzundangas e a sua ligação com a realidade política nacional. Narra a história de um país fictício, chamado Bruzundanga, que serve como alegoria para o Brasil. Dessa forma, a investigação abriu-se para o entendimento do papel do intelectual engajado na obra limiana e da afirmação do que constituiu a literatura militante, de protesto e de denúncia.

O período em que Barreto viveu e produziu sua obra estava lado a lado com a literatura como sorriso da sociedade. Mesmo sem escrever um tipo de literatura que era amplamente consumida, Barreto conseguiu ter algum retorno financeiro, pois era momento de profissionalização, de certa maneira, do literato. Os jornais pagavam pelos textos e, ao mesmo tempo, colocava-os em evidência, por isso, as ligações com a elite se estreitavam, levando muitos autores a optarem por temas mais leves e despretensiosos. Lima Barreto faz o oposto.

Entretanto, a ligação solidária que mantinha com os mais desfavorecidos não irá se manter em Os bruzundangas. Contrariando seu estilo, colocará em evidência os figurões do alto escalão, como o ministro e o Mandachuva, aqueles responsáveis pelo destino da nação fictícia. Todas as figuras poderosas serão registradas como ridículas e frívolas.

O ridículo no conto já começa com a escolha do nome: "Mas que diabo, que bruzundanga; será possível que este País, em essência, não mudou um milímetro 
nos últimos cinquenta e quatro anos?" (ANTONIO, 1977 p. 14). A frase é de um livro escrito há mais de cem anos, mas que se aplica perfeitamente no cenário político atual.

Lima Barreto usou o termo bruzundanga para mostrar a sua indignação com a realidade do país que ainda tem os mesmos problemas sociais e políticos que havia em 1922, quando da publicação da obra Os Bruzundangas. O termo, que significa “(...) Palavreado confuso; algaravia. 2. Mistura de coisas imprestáveis; mixórdia. 3. Confusão, embrulhada, trapalhada. 4. Cozinhado malfeito e repugnante. (...)" (HOLLANDA, 1986, p. 295), abandona o dicionário para virar título de um dos livros do literato e mostra a intenção do autor em dar tratamento irônico para a realidade que será mostrada no conto, além de dar um toque de estranhamento.

Os bruzundangas foi o último livro escrito por Lima Barreto e revela uma crítica mordaz à política da época, conforme aponta Bosi:

\begin{abstract}
Com Os bruzundangas Lima Barreto fez obra satírica por excelência. Valendo-se do feliz expediente de Montesquieu nas Cartas Persas, imaginou um visitante estrangeiro a descrever a terra de Bruzundanga, nada mais nada menos que o Brasil do começo do século. Escrita nos últimos anos, a obra traz forte empenho ideológico e mostra o quanto Lima Barreto podia e sabia transcender as próprias frustrações e se encaminhar para uma crítica objetiva das estruturas que definiam a sociedade brasileira do seu tempo $(1975$, p. 364).
\end{abstract}

A fascinação pelo mundo da ficção levou-o a criar um país e, ainda, levar o leitor a viajar por ele. No prefácio de Os bruzundangas, mostra as razões para tal viagem pela República dos Estados Unidos da Bruzundanga, que serviria de exemplo, ou melhor, antiexemplo para a nação brasileira:

\footnotetext{
Temos aqui ministros de Estado que são simples caixeiros de venda, a roubar-nos muito modestamente no peso da carne seca, enquanto a Bruzundanga os tem que se ocupam unicamente no seu ofício de ministro, de encarecerem o açúcar no mercado interno, conseguindo isto com o vendê-lo abaixo do preço da usina aos estrangeiros (BARRETO, 1956, p. 27).
}

O narrador, ao revelar os problemas da Bruzundanga e do Brasil, mostra uma personalidade fracionada, pois, ora é um jornalista preocupado, ora é cronista de viagem, pontuando os seus relatos com um intenso sarcasmo, como nessa declaração: "Pobre terra da Bruzundanga! Velha, na sua maior parte, como o planeta, toda a sua missão tem sido criar a vida e a fecundidade para os outros." (BARRETO, 1956, p. 29). 
Misturar crônicas de viagem com relato jornalístico seduz o leitor, pois os absurdos e as trapaças no relato do viajante na Bruzundanga tornam o texto curioso a ponto de despertar o interesse pela leitura. A intenção principal do narrador é desvendar todos os setores da nação visitada, particularmente as ações dos homens que intervêm no curso da vida em sociedade, ou seja, os figurões que mandam no país. Os olhos do narrador nunca se voltam para os aspectos positivos e sim para a idiotice, o ridículo e a maldade presente nos atos sociais, que podem ocorrer em virtude do descompromisso ético na política, na sociedade e na cultura.

Lima Barreto deixa transparecer na tessitura do conto que pretendia criticar, de maneira pertinente e real, o arremedo de república que aqui havia, as relações sociais e a política pervertida e, sobretudo, o caos da sociedade brasileira. Nesse propósito, o grotesco encaixa-se sob medida, conforme se pode notar no capítulo As eleições, em Os bruzundangas, em que o viajante observa:

Na capital da Bruzundanga, Bosomsy, onde assisti diversas eleições, o espetáculo delas é o mais ineditamente pitoresco que se pode imaginar. As ruas ficam quase desertas, perdem o seu trânsito habitual de mulheres e homens atarefados; mas para compensar tal desfalque passam constantemente por elas, carros. Automóveis, peja dos de passageiros heterogêneos (BARRETO, 1956, p. 114).

Parece que o efeito procurado por Lima Barreto era mostrar, através da Bruzundanga, a extravagância do Brasil. Se a data de publicação fosse ocultada, ter-se-ia um retrato da realidade brasileira atual:

\footnotetext{
Não há necessidade de ser muito enfronhado nos mistérios das patifarias comerciais e industriais, para ver logo quais as causas de semelhante encarecimento das unidades primordiais a nossa existência. Nunca o Brasil as produziu tanto e nunca elas foram tão caras. O plantador, o operário agrícola continua a ganhar o mesmo; mas o consumidor as estão pagando pelo dobro. Quem ganha? O capitalista. Ele e unicamente ele, porquanto o fisco mesmo continua a receber o mesmo ou quase o mesmo que antigamente (BARRETO, 1956, p. 191).
}

O narrador monta um quebra-cabeça em que as peças parecem não se encaixar e disseca todos os setores: a administração, a academia e a elite. Seu intento era mostrar a decadência de um país moldado pela corrupção e assolado por valores sociais invertidos e em que a sabedoria não é valorizada, como pode se perceber no trecho a seguir:

É sábio, na Bruzundanga, aquele que cita mais autores estrangeiros; e quanto mais de país desconhecido, mais sábio é. Não é, como se podia crer, aquele que assimilou o saber anterior e concorre para aumentá-lo com seus trabalhos individuais. Não é 
esse o conceito de sábio que se tem em tal país. Sábio, é aquele que escreveu livros com as opiniões dos outros. Houve um que, quando morreu, não se pôde vender-lhe a biblioteca, pois todos os livros estavam mutilados. Ele cortava-lhes as páginas para pregar no papel em que escrevia os trechos que citava e evitar a tarefa maçante de os copiar (BARRETO, 1956, p. 168).

O narrador dá um tratamento pejorativo para aqueles que deveriam receber o respeito, pois não o merecem, conforme fica nítido no decorrer do conto. Para justificar todo o desdém pelos figurões da República Bruzundanga, o narrador desnuda as ações da elite dirigente, sobretudo as mais estranhas, absurdas e ridículas, com o objetivo de desmascarar o quanto a elite desprezava as classes desvalidas e o futuro que teriam.

Além do ministro da agricultura, o narrador mira seus olhos no homem principal da República Bruzundanga, nomeado de Mandachuva, era um provinciano limitado (parecido com o atual governante do Brasil) escolhido entre os advogados para ascender ao poder. $\mathrm{O}$ escolhido para ser o governante de Bruzundanga deveria ser o mais medíocre, o que faz com que o narrador, inconformado, abandone o tom imparcial e discurse com toda a sua indignação:

\footnotetext{
É este homem cuja cultura artística se cifrou em dar corda no gramofone familiar, é este homem cuja única habilidade se resume em contar anedotas; é um homem destes, meus senhores, que depois de ser deputado provincial, geral, senador, presidente de província, vai ser o Mandachuva da Bruzundanga! (BARRETO, 1956, p. 90).
}

Atacando com voracidade a preparação (ou a falta de preparação) política do futuro Mandachuva que, durante a época que antecedia sua subida ao cargo, permanecia ocupado com intrigas políticas, tentando amansar os influentes e, também, procurando conseguir aliados, o narrador mostra que, na realidade, o poder estava nas mãos dos poderosos, pois eram eles que elegiam o presidente, daí optando pelos medíocres em detrimento dos inteligentes. Necessitavam de um fantoche no poder que poderia ser manipulado para atender às necessidades da elite, sem levar em consideração as necessidades do povo. Nota-se, assim, uma estreita relação com o que acontecesse nas eleições no país do carnaval, já que a pessoa que assume o cargo mais alto do país governa para a elite.

O narrador empenha-se em denunciar a aliança entre a imprensa e a elite do poder bruzundanguense, cuja função era promover os poetas e o Mandachuva e falar da beleza do doutor Karpatoso. A estratégia dos meios de comunicação era sempre deixar o Mandachuva em destaque nos jornais, dotando-o de qualidades que não tinha. Em troca, o governo pagava pelas publicações com dinheiro 
público. Aqui se nota que a imprensa apenas elogiava o governo, à semelhança do que acontece nos dias de hoje em alguns meios de comunicação do país.

Vê-se, então, a importância da presença de uma imprensa imparcial como forma de denunciar os problemas de uma nação, o que impera até o dia de hoje, mesmo que, atualmente, seja grande o desejo de muitos políticos, sobretudo aquele que ocupa o cargo mais alto, de coagir e ameaçar os repórteres, não só como forma de proteger a si, mas também aos seus. A contradição entre a publicidade sobre o país e a realidade é mostrada pelo narrador:

\footnotetext{
No entanto, a terra vive na pobreza; os latifúndios abandonados e indivisos; a população rural, que é a base de todas as nações, oprimida por chefões políticos, inúteis, incapazes de dirigir a cousa mais fácil desta vida.

Vive sugada, esfomeada, maltrapilha, macilenta, amarela, para que na sua capital, algumas centenas de parvos com títulos altinossantes disso ou daquilo, gozem vencimentos, subsídios [...] (BARRETO, 1956, p. 68).
}

O conto segue denunciando a incompetência do alto escalão, como o ministro Phrancisco Novilho (seria o nome uma referência ao filhote do boi e a sua inexperiência?) que, mesmo sendo um grande agricultor, não entendia nada de agricultura. Caso semelhante encontra-se na atualidade com um ministro da educação que escreve errado, um diretor de fundação de valorização da cultura negra que diminui os impactos da escravidão e um ministro da saúde que não é médico.

O narrador, sem papas na língua, expõe, de maneira vexatória, toda falta de conhecimento técnico do novo ministro da agricultura, flagrando-o em uma situação humilhante ao encontrar um entrave burocrático no ministério: “- Onde está aqui agricultura? ... Estes papéis ... Isto não é prático!... Quero cousas práticas! ... Canaviais... Engenhos... Qual! Isto não é prático! Vou fazer uma reforma!” (BARRETO, 1956, p. 101).

Implacavelmente, o narrador não deixa passar nenhuma ação absurda e maldosa de suas vítimas da alta cúpula e, dessa forma, denunciou a corrupção do ministro Novilho que se aproveitou de sua posição para ganhar dinheiro com a alta do açúcar no mercado internacional. Com o desaparecimento do político, o guarda-livros tomou-se responsável pela burocracia junto ao presidente, o que despertou a curiosidade do Chefe do Governo ao mesmo tempo em que revelou sua alienação: “- Onde está o doutor Phrancisco Novilho? - Está ocupado com coisas práticas.” (BARRETO, 1956, p. 102).

A República formada pelo alto escalão serve como um espelho para todo o cinismo dos dirigentes bruzundanguenses, já que tudo o que faziam tinha como 
intuito apenas o benefício próprio. A classe política já estava condenada pelos vícios arraigados na estrutura social da nação que transpareciam nos atos insólitos de financistas, ministros e do próprio presidente. Semelhanças com o governo de hoje não podem ser consideradas meras coincidências, mas sim um retrato real do caos que se instalou no país e parece não ter prazo para se encerrar.

Além dos políticos, o narrador também critica de maneira recorrente a cultura do café, mostrando a contradição sobre esse produto que, supostamente, era a maior riqueza de Bruzundanga: "O café é tido como uma das maiores riquezas do país; entretanto é uma das maiores pobrezas” (BARRETO, 1956, p. 70). Isso ocorria porque a elite obrigava o governo a utilizar dinheiro público para comprar café e mantê-lo em alta no mercado (fato que realmente ocorre entre o final no século XIX e início do XX e assemelha-se às atuais políticas de incentivo aos grandes bancos e empresas, que receberam bilhões do governo para que não quebrassem enquanto mantêm o povo à míngua). E como se pagava a conta para manter o café em alta? Como hoje em dia, sobrava para o povo através de impostos.

Na república do grotesco, quase uma distopia, a política assume uma grande parcela de responsabilidade nas circunstâncias vividas pela nação. Em A política e os políticos da Bruzundanga, o narrador repete a observação:

\footnotetext{
O país, no dizer de todos, é rico, tem todos os minerais, todos os vegetais úteis, todas as condições de riqueza, mas vive na miséria. [...] Por que será tal coisa? hão de perguntar. É que a vida econômica da Bruzundanga é toda artificial e falsa nas suas bases, vivendo o país de expedientes (BARRETO, 1956, p. 65).
}

Bruzundanga é um país de fachada, baseada em mentiras e recriada como um paraíso. E, neste paraíso, ocorre uma espécie de alienação entre seus membros, perpassando o povo enganado, os políticos que servem de fantoche e a elite que realmente governa. Ali, todos os problemas começavam e terminavam nas mãos de uma mesma classe: políticos corruptos, despreparados e incompetentes, o que conversa perfeitamente com a realidade atual do Brasil e com o conto $\mathbf{O}$ novo manifesto.

\section{O NOVO MANIFESTO OU A CARA DE PAU DOS POLÍTICOS BRASILEIROS}

"Eu também sou candidato a deputado. Nada mais justo. Primeiro: eu não pretendo fazer coisa alguma pela pátria, pela família, pela humanidade" (BARRETO, 2003, p. 15). É assim que se inicia o conto O novo manifesto. Qualquer ligação com a realidade política atual não é mera coincidência. Retrata 
um candidato a deputado fictício que nada pretende fazer e afirma que se algo fizesse seria condenado por seus colegas e os políticos da vida real que quase nada fazem.

Embora escrito há mais de cem anos, continua muito atual, pois trata de um candidato a deputado que nada pretende fazer e não tem nenhuma vergonha de admitir (o que mais se tem, hoje em dia, são políticos que nada fazem, mas não são sinceros o bastante para falar a verdade. Vide um certo deputado que, durante trinta anos, nada fez e chegou à presidência da república). Não contente, o candidato ainda diz que, se fizesse algo, os colegas ficariam contra ele:

Um deputado que quisesse fazer qualquer coisa dessas, ver-se-ia bambo, pois teria, certamente, os duzentos e tanto espíritos dos seus colegas contra ele.

Contra as suas ideias levantar-se-iam duas centenas de pessoas do mais profundo bom senso.

Assim, para poder fazer alguma coisa útil, não farei coisa alguma, a não ser receber o subsídio.

Eis aí em que vai consistir o máximo da minha ação parlamentar, caso o preclaro eleitorado sufrague o meu nome nas urnas (BARRETO, 2003, p. 15).

E segue afirmando que pretende dar uma boa vida à família e, assim, ajudar a humanidade:

Recebendo os três contos mensais, darei mais conforto à mulher e aos filhos, ficando mais generoso nas facadas aos amigos.

Desde que minha mulher e os meus filhos passem melhor de cama, mesa e roupas, a humanidade ganha. Ganha, porque, sendo eles parcelas da humanidade, a sua situação melhorando, essa melhoria reflete sobre o todo de que fazem parte (BARRETO, 2003, p. 15).

Pode parecer absurdo, mas o candidato realmente acha que manter a sua família feliz é uma maneira de manter a humanidade bem e todo mundo ganha. Ao final, se dirige aos possíveis eleitores:

Concordarão os nossos leitores e prováveis eleitores, que o meu propósito é lógico e as razões apontadas para justificar a minha candidatura são bastante ponderosas.

De resto, acresce que nada sei da história social, política e intelectual do país; que nada sei da sua geografia; que nada entendo de ciências sociais e próximas, para que o nobre eleitorado veja bem que vou dar um excelente deputado.

Há ainda um poderoso motivo, que, na minha consciência, pesa para dar este cansado passo de vir solicitar dos meus compatriotas atenção para o meu obscuro nome.

Ando mal vestido e tenho uma grande vocação para elegâncias. 
O subsídio, meus senhores, viria dar-me elementos para realizar essa minha velha aspiração de emparelhar-me com a deschanelesca elegância do senhor Carlos Peixoto. Confesso também que, quando passo pela Rua do Passeio e outras do Catete, alta noite, a minha modesta vagabundagem é atraída para certas casas cheias de luzes, com carros e automóveis à porta, janelas com cortinas ricas, de onde jorram gargalhadas femininas, mais ou menos falsas.

Um tal espetáculo é por demais tentador, para a minha imaginação; e, eu desejo ser deputado para gozar esse paraíso de Maomé sem passar pela algidez da sepultura.

Razões tão ponderosas e justas, creio, até agora, nenhum candidato apresentou, e espero da clarividência dos homens livres e orientados o sufrágio do meu humilde nome, para ocupar uma cadeira de deputado, por qualquer Estado, província, ou emirado, porque, nesse ponto, não faço questão alguma.

Às urnas (BARRETO, 2003, p. 15).

O absurdo do conto é tão grande que o candidato a deputado bem poderia ter nascido em Bruzundanga. O conto continua sendo absurdamente atual, pois, ainda hoje, os políticos, com raríssimas exceções, ainda recebem gordos salários, com grandes acréscimos com bonitos nomes de verba de gabinete, auxílio-paletó e, pasmem, até mesmo auxilio-moradia, mesmo que tenham apartamentos funcionais (utilizados para comer gente, como disse certo deputado à boca pequena). Se não bastassem as verbas absurdas, mas legalizadas, ainda há o famoso caixa dois e a propina.

Lima Barreto parecia adivinhar, quando escreveu o conto, que a política, nos anos vindouros, continuaria como prática ortodoxa, mas desonesta. Entre a Literatura e a História, a sua escrita foi cumprindo os seus passos, traçando um novo caminho dentro do mapa de produção da literatura nacional. Sua escrita é engajada e procura não enxergar somente o lado hegemônico da construção da sociedade, que é fortalecido pela cultura dominante, mas também visualizar, de forma crítica, seu objeto histórico de forma múltipla, repleto de manifestações culturais.

Para Benjamin (1994, p. 224), conhecer historicamente o passado não quer dizer saber como ele de fato foi. Quer dizer que se apropria de uma recordação, uma pálida lembrança de um período. Lima Barreto abre-se para a prática de interferir de modo que possa protestar durante o período que viveu e deixá-lo para a posteridade.

\section{CONSIDERAÇOEES FINAIS}

Os bruzundangas e $\mathbf{O}$ novo manifesto podem, perfeitamente, representar os dias de hoje, pois mostram as eternas mazelas da política brasileira de forma 
irônica e até debochada. Na República das Bruzundangas, o presidente se destaca por conta de sua completa falta de capacidade para governar, sendo chamado de Mandachuva. Aqui, na República das bananas, o mito, ostentando a sua faixa presidencial mostra total inépcia para o cargo que ocupa e a semelhança com aquele não é só mera coincidência.

O narrador mostra, de maneira sardônica, que os políticos da República dos Estados Unidos da Bruzundanga, principalmente os que ocupam altas posições, acham-se acima do bem e do mal, supondo-se diferentes e melhores que os demais, ou seja, a elite sempre sendo superior ao povo. Os políticos e seus aliados praticam o nepotismo, à semelhança do que acontece no Brasil em todas as esferas.

Bruzundanga, o país do surreal, tinha a elite formada pelos doutores (todos aqueles que tinham conseguido um diploma ou os pseudodoutores) e os novos ricos (que viajavam para a Europa e retornavam com títulos de nobreza). A política era uma piada. Em uma pseudodemocracia, o povo escolhia, mas não tinha a mínima noção do que estava fazendo (como na atualidade. $\mathrm{O}$ atual governo não deixa margem para dúvida.) O presidente tratado por Mandachuva (o título de mito cairia bem) entrou na política por nepotismo, graças ao sogro, que queria garantir um bom cargo para as filhas (mais fidedigno à realidade, impossível). $\mathrm{O}$ presidente ignorante, assim que assume o cargo, rodeia-se de seus asseclas. Cargos públicos eram entregues aos montes para candidatos que não tinham a melhor qualificação.

Os pequenos bruzundanguenses aprendiam que viviam em um país cheio de riquezas naturais. O que não aprendiam é que essas riquezas não eram utilizadas. Tudo se comprava pronto. As Forças Armadas funcionavam na famosa base de muito cacique para pouco índio, pois tinham dezenas de comandantes e eram pacifistas e humanizadas.

Criado com a finalidade de denunciar os problemas da República brasileira, o texto de Lima Barreto funcionou perfeitamente, atingindo o objetivo desejado, a partir do momento em que desmoraliza o espírito falsamente patriota daqueles que diziam defender o país, quando, na verdade, estavam destruindo. Ao denunciar os problemas da nação, o autor pagou o preço de não ser tão apreciado, mas cumpriu a sua missão, diferente de outros autores que não dissertavam sobre o país.

No conto Riquezas da Bruzundanga, observa que "quando se lê qualquer poema patriótico desse país, ficamos com a convicção de que essa nação é mais rica da terra" (BARRETO, 1956, p. 69). Isso remete a uma imagem do Brasil 
que, durante muitos anos, ficou no imaginário dos estrangeiros. Pero Vaz de Caminha, em sua carta para o rei de Portugal, já pintava maravilhas sobre a nova terra encontrada, sobre as riquezas naturais e a fertilidade da terra, o que é corroborado pelo trecho a seguir: "assim todas as plantas úteis nascem na nossa Bruzundanga com facilidade e rapidez, proporcionando ao estrangeiro a sensação de que ela é o verdadeiro paraíso terrestre" (BARRETO, 1956, p. 69). Hoje, diante da realidade que o país vive, graças à incompetência de quem o governa, essa imagem de paraíso já começou a cair por terra.

É primordial pensar na arte como fonte de denúncia, protesto e resistência e pensar em como Lima Barreto fez isso de forma magistral. Munido de pena e papel, com humor ácido e sem papas na língua, o autor não teve medo de escrachar e remar contra a corrente à medida que ia denunciando os problemas do Brasil, usando a ironia para desmoralizar os políticos que faziam o mesmo com o Brasil. É uma pena que o autor não tenha tido o reconhecimento necessário ainda em vida. Realidade essa que atingiu outros escritores que ousaram transcender o mundo cor-de-rosa da elite e produzir uma literatura que tinha como objetivo não apenas entreter, mas levar a uma reflexão crítica sobre o mundo.

Hutcheon (1991, p. 198) aponta que a "metaficção historiográfica não pretende reproduzir acontecimentos, mas, em vez disso, orientar-nos para os fatos, ou para novas direções a tomar, para que pensemos sobre os acontecimentos". E foi exatamente isso que Lima Barreto procurou fazer com seus contos.

\section{REFERÊNCIAS}

ANTONIO, João. Calvário e porres do pingente Afonso Henriques de Lima Barreto. São Paulo: Civilização brasileira, 1977.

ASSIS, Machado de; BARRETO, Lima \& etc. O Novo Manifesto - Antologia de Contos e Crônicas. São Paulo: Martins Fontes, 2003.

ATHAYDE, Tristão de. Contribuição à história do modernismo: o prémodernismo. Vol. I. Rio de Janeiro: José Olympio, 1939.

BARRETO, Lima. Os bruzundangas. São Paulo: Brasiliense, 1956.

BENJAMIN, Walter. Sobre o conceito de História. In: Magia e Técnica, Arte e Política. São Paulo: Brasiliense, 1994.

BOSI, Alfredo. História concisa da literatura brasileira. São Paulo: Cultrix, 1975. 
CANDIDO, Antonio. Educação pela noite \& outros ensaios. São Paulo: Ática, 1987.

HOLLANDA, Aurélio Buarque de. Dicionário da língua portuguesa. Rio de Janeiro: Nova Fronteira, 1986.

HUTCHEON, Linda. Poética do pós-modernismo: história, teoria e ficção. Rio de Janeiro: Imago Ed., 1991.

LINS, Osman. Lima Barreto e o espaço romanesco. São Paulo: Ática, 1976.

ORTIZ, Renato. Imagens do Brasil. In: Revista Sociedade e Estado - v. 28, n. 3 Setembro/Dezembro 2013. Disponível em: http://www.scielo.br/pdf/se/v28n3/ a08v28n3.pdf. Acesso em: 08 jun. 2020.

SANTIAGO, Silviano. Uma literatura nos trópicos. São Paulo: Rocco, 2000. 
